\title{
Evaluating buildings' solar energy potential concerning urban context based on UAV photogrammetry
}

\author{
Yunsong $\operatorname{Han}^{1,2}$, Yongjie Pan ${ }^{1,2}$, Tianyu Zhao ${ }^{1,2}$, Cheng Sun ${ }^{1,2}$ \\ ${ }^{1}$ School of Architecture, Harbin Institute of Technology, Harbin, China, Email: suncheng@hit.edu.cn \\ ${ }^{2}$ Key Laboratory of Cold Region Urban and Rural Human Settlement Environment Science and \\ Technology, Ministry of Industry and Information Technology, Harbin, China
}

\begin{abstract}
This paper presents a method to model urban context automatically based on UAV photogrammetry and quantify urban context effect on solar radiation received by buildings. This methodology goes from images acquisition to the urban context model, to end with the estimates of solar radiation production. The proposed method was applied to a case study in Harbin. The results showed that the urban context model generated by aerial images satisfies the accuracy and efficiency requirement of solar energy potential evaluation. This study will enable energy investors to accurately identify the solar energy potential and suitable locations of solar photovoltaic power generation equipment on building surfaces.
\end{abstract}

\section{Introduction}

The rapid development of cities requires the continuous guarantee of energy supply. With the depletion of fossil fuels and the increasing emphasis on environmental protection by human, solar energy has become an effective alternative to clean energy (Kannan et al., 2016). With the development of the urban in vertical and intensive direction, the distribution of solar radiation in the urban areas is highly uneven as the obstructions to the incoming sunlight. The shadow of adjacent buildings, plants and urban facilities seriously affect the solar irradiance acquired on the building surface. Estimating the amount of solar radiation available on different building surfaces has an important role in evaluating the feasibility of distributed photovoltaic energy equipment in urban built-up environment. At the same time, the calculation of the solar potential concerning urban context is conducive to raising people's understanding of the shape of the building itself and the relationship between the road trees and the building facade, thus assisting urban planning and landscape design.

However, due to the two-dimensional characteristics of traditional evaluation methods, the building facade structure and urban context cannot be represented, so it is difficult to use these methods to calculate the solar potential of the building facade concerning urban context. As the detailed and accurate urban context model could support the designer to handle the complex shadow patterns projected by urban context, the related work pointed out that the $3 \mathrm{~d}$ model of the urban context should be used as an alternative input data to improve the accuracy of the solar energy potential evaluation for building in high-density urban areas (Freitas et al., 2015). This is also supported by Rodriguez et al. (2017) who proposed a new methodology to assess the solar potential at urban level based on $3 \mathrm{~d}$ model and conclude the higher the level of the detail of the buildings the more accurate the PV estimations.

The development of Light Detection and Ranging (LiDAR) technology make it possible to build $3 \mathrm{~d}$ model of urban context due to its high scene reproduction capability. Carneiro et al. (2009) proposed a method from the extraction of Light Detection and Ranging (LiDAR) data to the environmental analysis of urban models and the visualization of solar potential results, while this study did not discuss the effects of vegetation on building facades. Besides, the point cloud obtained by the airborne LiDAR has no color information (RGB), which not conducive to the later point cloud semantic distinction. Redweik et al. (2013) developed a 3D urban model built from LiDAR data and simulated the solar radiation of campus buildings, while the effect of urban context wasn't singled out for consideration with this model. Zhang et al. (2015) evaluated the solar energy potential at the building scale considering the effect of vegetation based on the LiDAR point cloud data and QuickBird imagery. However, all the above-mentioned works simplified the urban context since the urban model is built using a point cloud data and no information can be obtained on details of the facades such as windows, doors or balconies, which are important for any solar panel installation (Machete et al., 2018). Meanwhile, the obtaining of LiDAR is high cost and large demand of professional operations, which is difficult to popularize and apply. Airborne LiDAR equipment is usually bulky and heavy, requiring the aircraft with a higher load capacity. To better represent the details of the building, it often takes a lot of time to do manual modeling, while manual modeling is not a good choice for a wide range of simulation objects. LIDAR data have high accuracy in geometric ranging, but the resolution of point position will be lower when the scanning distance is long.

With the popularization of small multi-rotor UAVs and the development of low-altitude photogrammetry technology, considerable attention has been paid to building information acquisition based on UAV photogrammetry (Ruzgienè et al., 2015). Image-based building information acquisition technology relies on images acquired by relatively small and lightweight 
camera, which is much more convenient than the manual measurement and light detection and ranging. $3 \mathrm{~d}$ modeling based on UAV photogrammetry can better describe the ground objects without significant simplifications in the building facades geometry as the improvement of reconstruction algorithm in computer vision and graphics. Zhang et al. (2017) proposed the method of geometrical information gathering in buildings based on the 3-dimensional (3D) geometrical reconstruction, which is suitable for the evaluation of existing building applied photovoltaic (BAPV) potential with high feasibility and accuracy. Szabó et al. (2016) assessed the opportunities available to exploit solar radiation on roofs with both LiDAR and photogrammetry techniques, and proved that the approaches of photogrammetry technique high accuracy and efficiency of solar radiation values calculated.

Thanks to the scene reduction ability of UAV photogrammetry, accurate representations of man-made construction, terrain and vegetation comes to possibility. UAV photogrammetry could evaluate the solar radiation potential of buildings concerning the impact of urban context. This paper proposed a method to generate detailed urban context model from UAV photogrammetry and to integrate this model into solar energy potential simulation for buildings considering the shading cast by tree and nearby buildings.

\section{Method}
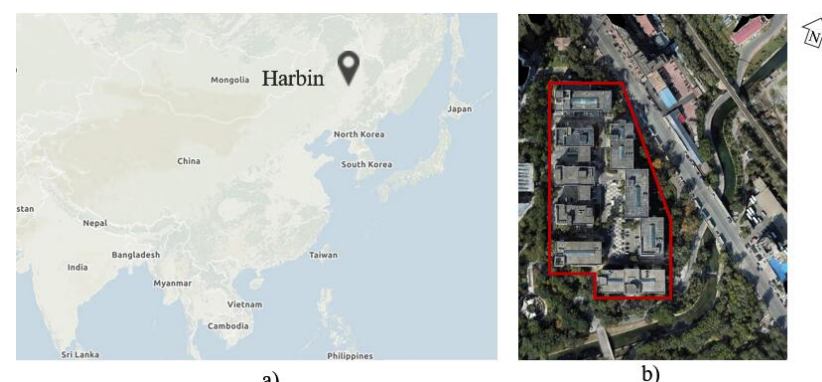

Figure 1: Location and building layout of the study area. a) Location of Harbin, b) Building layout of study area.

The urban context model is reconstructed from the aerial image using SFM and MVS algorithms which could be directly applied to the solar radiation simulation. To ensure the credibility of the subsequent results, the accuracy of the modeling and simulation were both verified with the measured data. A case study was conducted to demonstrate the applicability of the proposed method. Considering the vegetation changes in winter and summer, the environmental data were collected in two times to facilitate the later comparative analysis.

The selected area for the study was a research center with relatively complex surroundings covered approximately 4.7 ha (Latitude 45.7N, Longitude 126.6 E) (Fig. 1). This area represents a typical urban neighborhood, composed of 9 office buildings and many tall deciduous trees. The height of the buildings are mainly about 20 meters. Due to the effects of nearby buildings and vegetation, the amount of solar radiation obtained on each building is of great uneven distribution.

\section{Urban context modelling}

Urban context modeling includes two parts: image acquisition and image-based reconstruction. Image acquisition is the premise of urban context modeling.

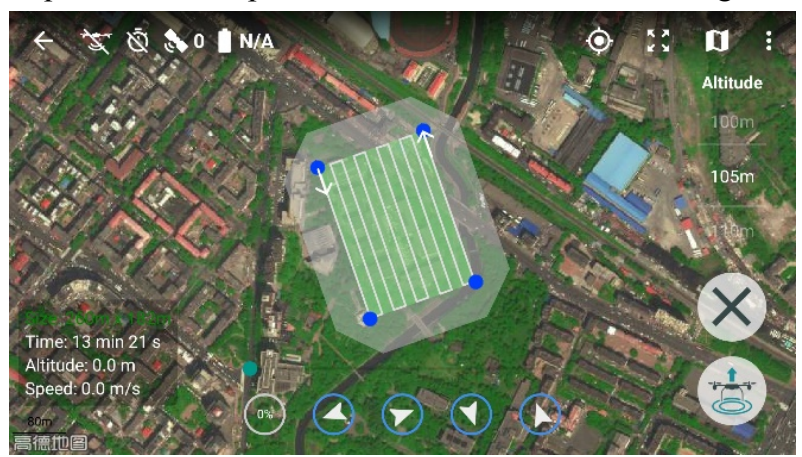

Figure 2: Route planning layout generated by Altizure.

Prior to the UAV takeoff, route planning was done as shown in Fig. 2 using Altizure. To avoid the filming occlusion of traditional aerial photography and shooting dead angle, this study adopted the single-camera oblique photogrammetry method to ensure better quality of image acquisition. A single high-pixel camera mounted on the UAV was used to shoot the ground from front to back, left, right and vertical. Images were acquired autonomously based on ground control parameters and camera settings summarized in Table 1.

Table 1: Flight, camera and ground control parameters summary.

\begin{tabular}{|c|c|c|c|}
\hline \multicolumn{2}{|l|}{ Flight parameters } & \multicolumn{2}{c|}{ Camera settings } \\
\hline Altitude & $105 \mathrm{~m}$ & Resolution & $5472 * 3648$ \\
\hline $\begin{array}{l}\text { Forward } \\
\text { Overlap }\end{array}$ & $80 \%$ & $\begin{array}{c}\text { Exposure } \\
\text { Time }\end{array}$ & $1 / 500 \mathrm{~s}$ \\
\hline Side Overlap & $80 \%$ & Aperture & $\mathrm{f} / 5.6$ \\
\hline Camera Angle & $30^{\circ}$ & ISO & 100 \\
\hline
\end{tabular}

The aircraft may experience instability such as wobbling, deviations from course, and acceleration changes that result in motion blur and chromatic aberration in the UAV image. The blurred images would bring errors to the feature matching in the process of point cloud generation and affect subsequent processing. On the premise of ensuring the integrity of image stitching, the unsuitable image for reconstruction were discarded.

Image-based reconstruction was created from the set of RGB images, using ContextCapture which integrate multiple reconstruction algorithms include SFM algorithm, running on a Windows 7, with 64 GB of RAM and a six-core $4.0 \mathrm{GHZ}$ processer. The processing workflow of ContextCapture is illustrated in Fig. 3. First, import all photos and POS data used in the project. The camera parameters of the photo would be recognized automatically after importing the photo. For photos do not have these parameters written, it's necessary to manually define the camera's sensor size and focal length to complete the camera calibration. For the areas with 
control points, tag the control points and checkpoints in the photo and import the coordinates of these points. An effective set of control points consists of three or more control points, each of which requires two or more image punctuation points. Secondly, perform preliminary Aerotriangulation processing. For the drone using the GPS information, use photo positioning metadata for rigid registration for the positioning and georeferencing that set in the Aerotriangulation.

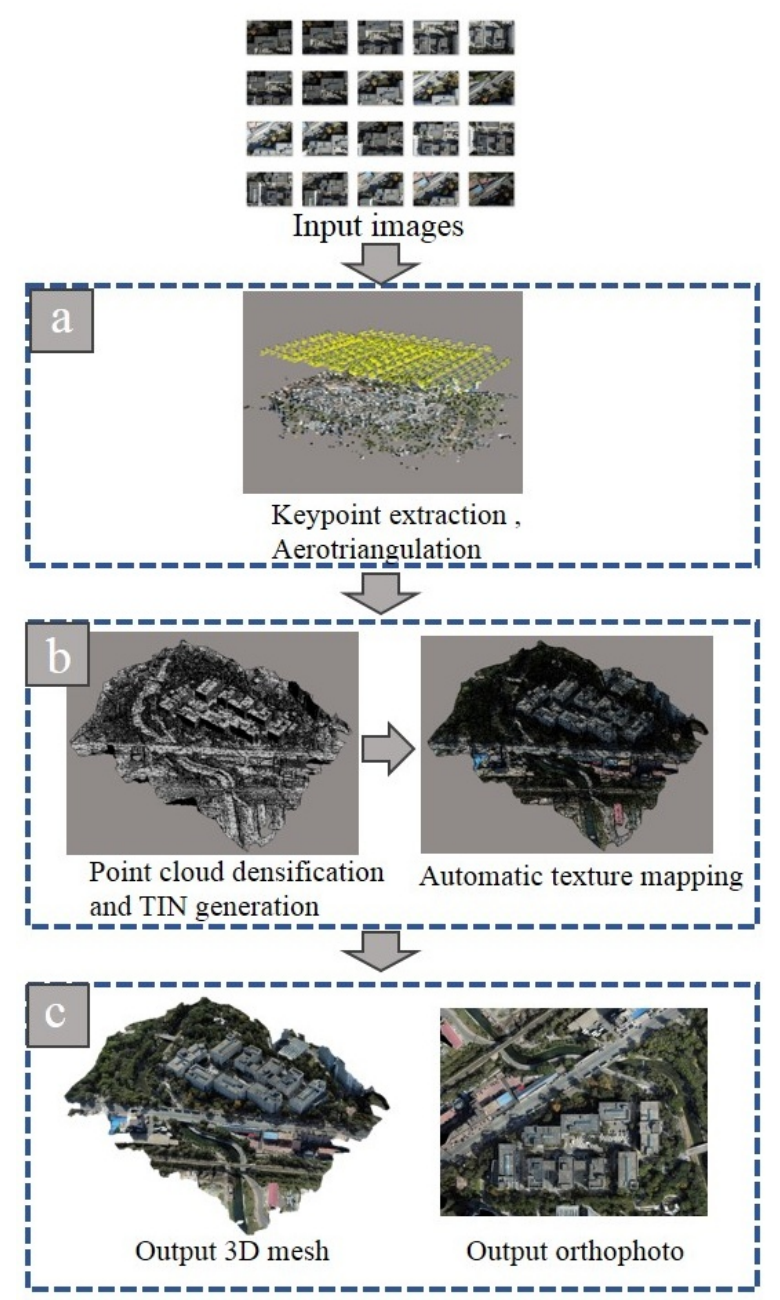

Figure 3: ContextCapture processing workflow.

Before proceeding to the next step, it is necessary to check the results of Aerotriangulation in the $3 \mathrm{D}$ view of the feature points. Finally, run the Reconstruction to create a 3D model. The Reconstruction allows for Adaptive Tiling, which creates tiles to process individually to maintain RAM space (Becker et al., 2018). In the Reconstruction parameter setting, set the parameter of "Geometric simplification" to "Planer", which can make the pavement flatter and the reconstructed buildings at right angles in the reconstruction scene. However, it also leads to the broken triangular mesh of the model, which will seriously reduce the display effect for some models. For subsequent processing, the output format of the model was set to FBX.

\section{Solar radiation simulation}

The commonly software used for solar radiation simulation includes Ecotect \& Geco, DIVA, Ladybug etc.
Table 2 shows the comparison between simulation software. Geco shows a disadvantage in terms of visualization and climate analysis, while DIVA and Ladybug are balanced in all aspects of comparison. To achieve the accuracy and efficiency of solar radiation simulation, the solar modeling was run with the Ladybug plugin.

Table 2: Comparison between simulation software.

\begin{tabular}{|c|c|c|c|}
\hline Software & Geco & DIVA & Ladybug \\
\hline Visualization & & $\star$ & $\star$ \\
\hline Orientation & $\star$ & $\star$ & $\star$ \\
\hline Climate analysis & & $\star$ & $\star$ \\
\hline Accuracy & $\star \star$ & $\star \star \star$ & $\star \star \star$ \\
\hline
\end{tabular}

$\star$ represents processing capacity.

The solar radiation analysis implemented in Ladybug was based on the cumulative sky approach (Robinson et al., 2004). The total solar radiation falling on the test model and the amount at each test point on the surfaces are accumulated. The boundary conditions of the simulation including the surrounding urban context, the calculation parameters and meteorological data extracted from the EnergyPlus Weather file (.epw). The result of the final visualization is presented in the form of a colored analysis grid. The related parameters in this paper were set as follows in Table 3.

Table 3: Summary of parameters used for Ladybug.

\begin{tabular}{|c|c|c|}
\hline Module & Parameters & Parameter input \\
\hline $\begin{array}{l}\text { Ladybug } \\
\text { Open EPW }\end{array}$ & -open & $\begin{array}{c}\text { CHN_Heilongjian } \\
\text { g.Harbin.epw }\end{array}$ \\
\hline \multirow{4}{*}{$\begin{array}{l}\text { Ladybug } \\
\text { _Analysis } \\
\text { Period }\end{array}$} & from Month & 1 \\
\hline & from Day & 1 \\
\hline & to Month & 12 \\
\hline & to Day_ & 31 \\
\hline \multirow{4}{*}{$\begin{array}{l}\text { Ladybug } \\
\text { Radiation } \\
\text { Analysis }\end{array}$} & geometry & Mesh input \\
\hline & context & Mesh input \\
\hline & grid Size & 1 \\
\hline & disFromBase & 0.01 \\
\hline
\end{tabular}

In this paper, the meteorological data in Harbin were adopted to ensure the real climate environment for the simulation. The triangular mesh model produced in the previous step was used as input of analysis geometry. For the analysis period, it can be one hour, one day or one year, which is set according to the needs of the result. For solar radiation simulation in a large-scale area, the grid size can be set to $0.5-4 \mathrm{~m}$. The smaller the grid size is, the more accurate the calculation is, but the calculation time may be longer. Distance from the base was the distance by which the object is shifted in the normal direction. Generally, set a relatively small value. When the model was more complex and the grid size was relatively small, it was suggested to open the parallel option and the calculation speed would be accelerated. The result of the calculation was displayed in the colored mesh with the corresponding legend and stored in Grasshopper. The solar radiation simulation workflow is shown in Fig. 4. 


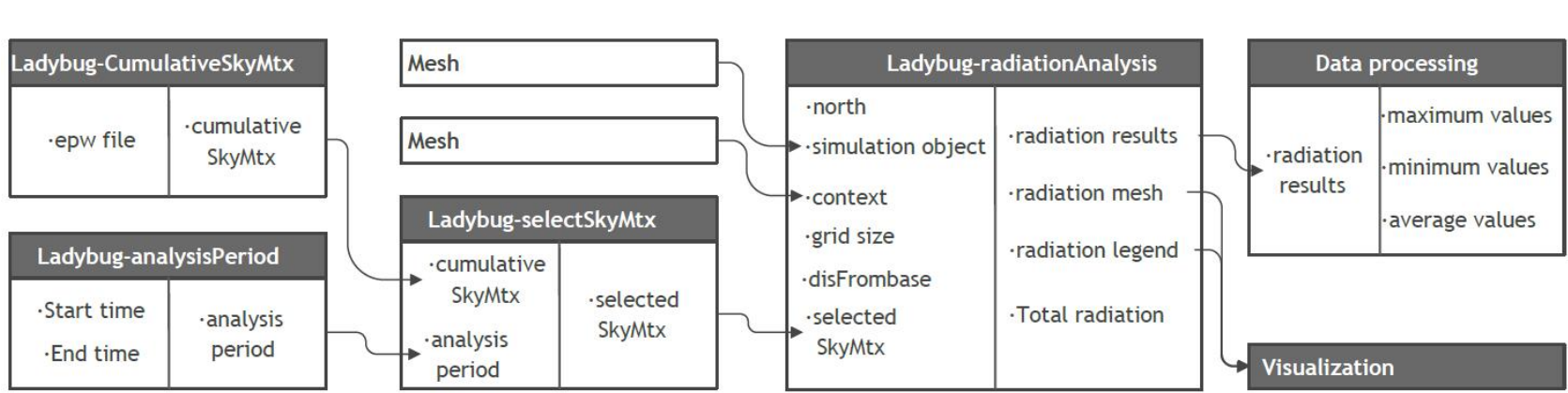

Figure 4: solar radiation simulation program.

\section{Validation}

To verify the geometric accuracy of the photo reconstruction, 9 feature sizes in four different areas of the site were selected for actual measurement. The measured position and serial number of the actual measurement was marked on the reconstructed model (Fig. 5). There is a comparison between actual measurement and data from acquisition of UAV photogrammetry to acquire a onedimensional standard deviation. The formula of standard deviation was shown as follows:

$$
\theta_{i}=\frac{u_{i}}{v_{i}} \times 100 \% ; \delta=\sqrt{\frac{\sum_{i=1}^{n} \theta_{i}{ }^{2}}{n}}
$$

Where $n$ is the data size, $u_{\mathrm{i}}$ is the difference value between the acquisition of UAV photogrammetry and actual measurement $\left(v_{\mathrm{i}}\right), \theta_{\mathrm{i}}$ is the percentage error magnitude, and $\delta$ is the standard percentage difference.
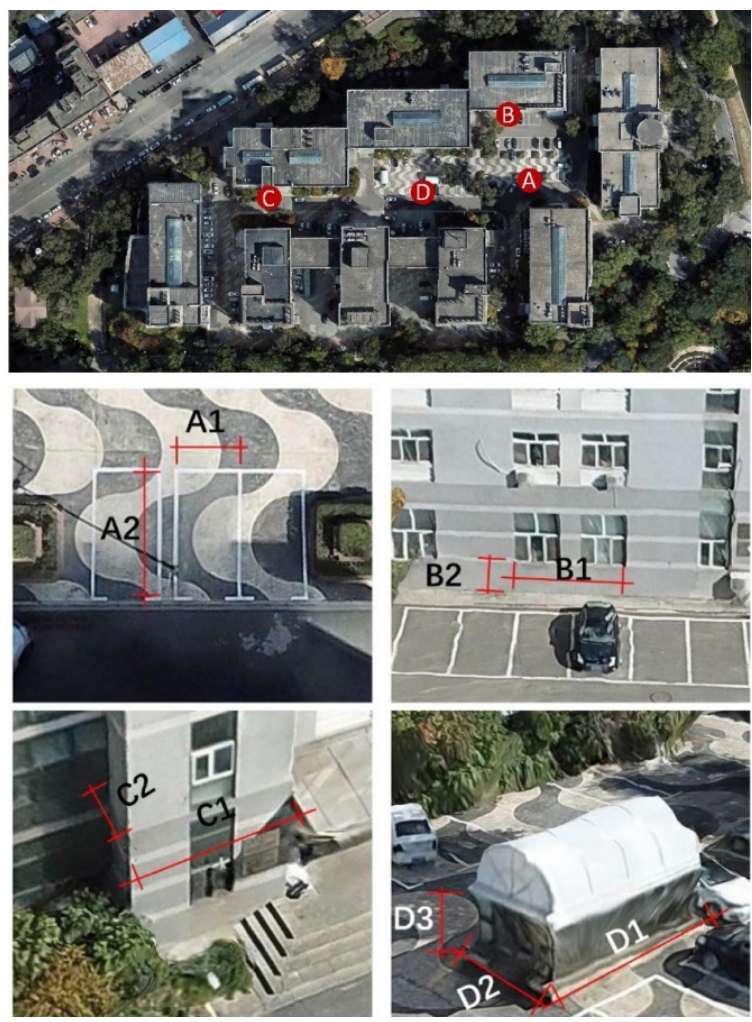

Figure 5: The measured position and serial number of the actual measurement marking on the reconstructed model.
Before proceeding further work, the simulation results were carefully analyzed to determine its accuracy and scale. In the comparative analysis, the prediction accuracy of the solar radiation simulation result was verified by comparing the measured values with the simulated values of the four representative solar terms.

The solar radiation measurements were performed on the campus located in Shuangcheng District in Harbin (Latitude 45.5N, Longitude 126.6 E), Harbin. Measuring instruments were placed on rooftops which are not shaded by the surrounding buildings. The hourly cumulative value of solar radiation at the facility were used. To ensure the consistency of verification conditions, roof surfaces with the same conditions in the study area were also selected as the simulated test points. To ensure the accuracy of the simulation results, the actual on-site measured weather data collected by the weather station is used in simulation. Linear regression analysis was used to analyze the correlation of the simulated values and measured values.

\section{Results and discussion}

\section{The accuracy and efficiency of urban context modeling}

Five flights were completed by the UAV, with the flying height about $105 \mathrm{~m}$ and a duration of $60 \mathrm{~min}$ at the time of acquisition. At the end, a total of 444 aerial photographs were acquired by UAV. The results of urban context modeling were shown in Fig. 6.

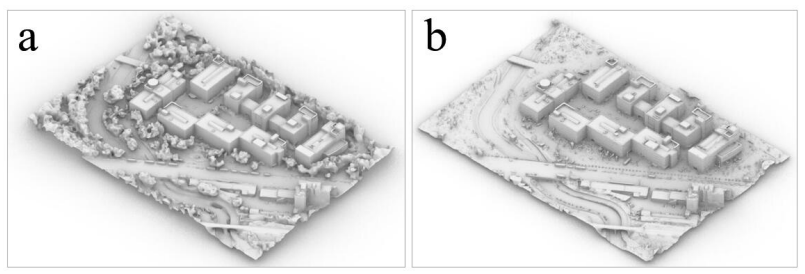

Figure 6: The results of urban context modeling. (a)summer, (b)winter

According to the Table 4, it could be observed that a mean accuracy of $98.33 \%>95 \%$. The mean accuracy was kept in an acceptable range demonstrated that UAV photography could be used for acquiring geometry information of buildings precisely. 
Table 4: Comparison between actual measurement and UAV photogrammetry.

\begin{tabular}{|c|c|c|c|}
\hline Number & $\begin{array}{c}\text { Acquisition } \\
\text { of actual } \\
\text { measurement } \\
\text { (m) }\end{array}$ & $\begin{array}{c}\text { Acquisition of } \\
\text { UAV } \\
\text { photogrammetry } \\
\text { (m) }\end{array}$ & $\begin{array}{c}\text { Accuracy } \\
\text { (\%) }\end{array}$ \\
\hline A1 & 2.43 & 2.36 & $97.12 \%$ \\
\hline A2 & 4.90 & 4.86 & $99.18 \%$ \\
\hline B1 & 4.95 & 4.97 & $99.60 \%$ \\
\hline B2 & 1.53 & 1.54 & $99.35 \%$ \\
\hline C1 & 5.03 & 4.99 & $99.20 \%$ \\
\hline C2 & 1.20 & 1.21 & $99.17 \%$ \\
\hline D1 & 6.05 & 5.89 & $97.36 \%$ \\
\hline D2 & 3.40 & 3.33 & $97.94 \%$ \\
\hline D3 & 2.30 & 2.21 & $96.09 \%$ \\
\hline
\end{tabular}

Image-based reconstruction processing time and number of triangular meshes produced from each image set are shown in Table 5. Processing time includes aero triangulation time and reconstruction time. The reconstruction time accounts for most of the processing time as the dense point cloud generation is timeconsuming. The aerotriangulation step only took approximately one tenth of the total processing time required. Processing time and number of triangular meshes increased with the number of images in each set. As the number of images doubles, processing time increases in multiples.

Table 5: The processing time and number of triangular meshes for each image set processed.

\begin{tabular}{|c|c|c|c|}
\hline $\begin{array}{c}\text { Image } \\
\text { Set }\end{array}$ & $\begin{array}{c}\text { Aerotriangul- } \\
\text { ation } \\
\text { Time(min) }\end{array}$ & $\begin{array}{c}\text { Reconstructi } \\
\text {-on } \\
\text { Time (min) }\end{array}$ & $\begin{array}{c}\text { Number of } \\
\text { triangular } \\
\text { meshes }\end{array}$ \\
\hline 111 & 3 & 47 & 183891 \\
\hline 222 & 6 & 99 & 420538 \\
\hline 444 & 11 & 204 & 521022 \\
\hline
\end{tabular}

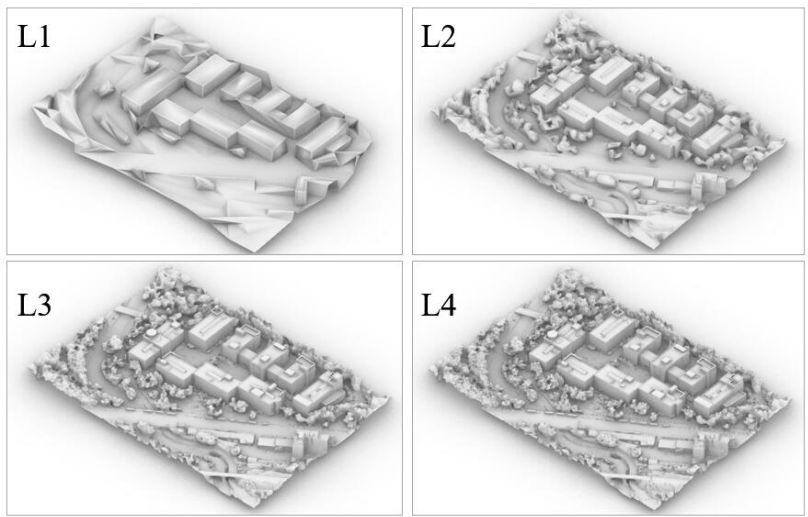

Figure 7: Triangular mesh models with different levels of detail.

For the set of 444 images, Fig. 7 shows the obvious differences between the 3D models of different levels of detail. As the level increases, the details of the building are enriched. The surrounding vegetation is also characterized by simple geometry to more complex shapes that are closer to reality. As the level increases, the modeling time also becomes longer. When the grade reaches the L3 level, the basic characterization of the building tends to be saturated. For 3D modeling of large scenes, using detailed level modeling can reduce the operating pressure of large data volume. The higher the level of detail of the model, the finer the reconstruction effect is, but the more meshes the model has, which is a great consumption of computing resources. For the smallscale solar radiation simulation conducted in this paper, the L3 level can better meet the accuracy requirements

\section{Analysis of simulation accuracy and efficiency}

Fig. 8 displays a simulation example of a mass model compared to a L3 model. Although the surface of the detail model is not very flat when compared to the mass model, the results of the simulation are very close to the mass model, which is acceptable. Moreover, this model has more details than the mass model, such as the bulges of the roof and facade.

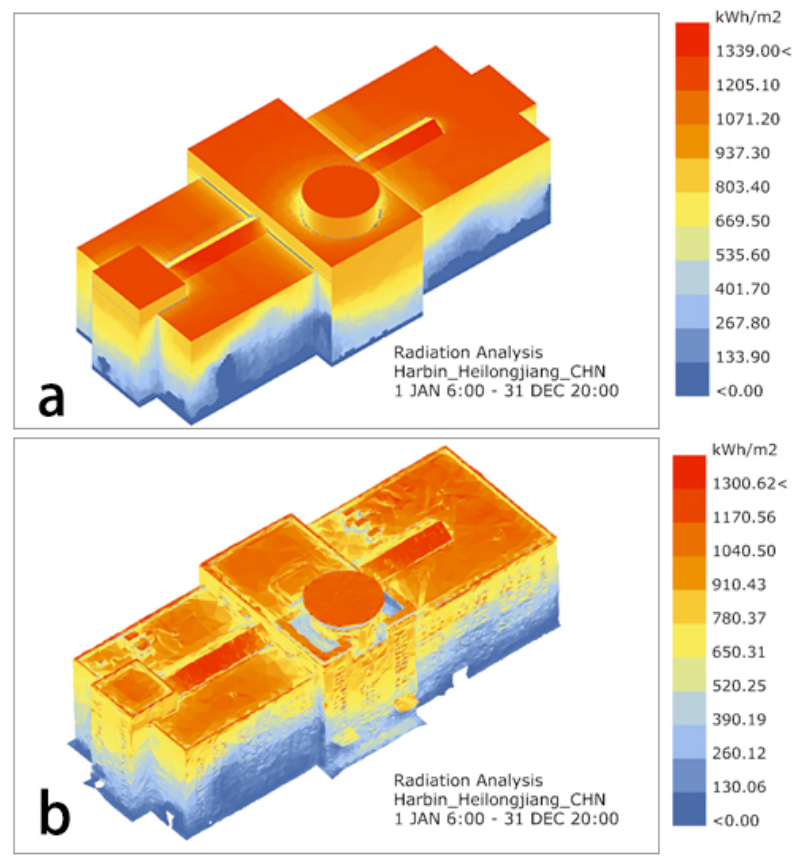

Figure 8: Mass model(a) compared to a detailed model(b).

It is evident from the Table 6 that the level of detail of the model has a significant impact on the simulation time. The simulation time is greatly increased as the level of detail of the model increases, and the smaller the grid size, the longer the simulation time is consumed, but the amount of time influenced is relatively small.

Table 6: Simulation time consumption of triangular mesh models with different levels of detail.

\begin{tabular}{|c|c|c|c|}
\hline $\begin{array}{c}\text { Model } \\
\text { detail } \\
\text { level }\end{array}$ & $\begin{array}{c}\text { Number of } \\
\text { triangular } \\
\text { mesh faces }\end{array}$ & $\begin{array}{c}\text { Grid size } \\
(\mathbf{m})\end{array}$ & $\begin{array}{c}\text { Simulation } \\
\text { time } \\
\text { consumption } \\
\mathbf{( ~ s ) ~}\end{array}$ \\
\hline \multirow{2}{*}{ L1 } & \multirow{2}{*}{520} & 0.5 & 0.26 \\
\cline { 3 - 4 } & & 1 & 0.25 \\
\cline { 3 - 4 } & & 2 & 0.24 \\
\hline \multirow{2}{*}{ L2 } & \multirow{2}{*}{5210} & 4 & 0.22 \\
\cline { 3 - 4 } & & 1 & 5.5 \\
\hline
\end{tabular}




\begin{tabular}{|c|c|c|c|}
\hline \multirow{3}{*}{ L3 } & & 2 & 4.7 \\
\cline { 3 - 4 } & \multirow{3}{*}{52102} & 4 & 4.4 \\
\hline \multirow{3}{*}{ L4 } & & 0.5 & 12.7 \\
\cline { 3 - 4 } & & 1 & 12.3 \\
\cline { 3 - 4 } & \multirow{3}{*}{521022} & 4 & 11.8 \\
\cline { 3 - 4 } & & 0.5 & 11.5 \\
\cline { 3 - 4 } & & 1 & 166.4 \\
\cline { 3 - 4 } & & 2 & 146.8 \\
\cline { 3 - 4 } & & 4 & 131.5 \\
\hline
\end{tabular}

When the meshes come to large number, performing solar radiation simulation will greatly consume the RAM of computer, or even leading to errors. Since the details of the L3 model are well preserved and the simulation time for solar radiation is relatively short, the L3 level of detail is selected as the recommendation for solar radiation simulation. For grid size selection, a grid size that is too large may neglect the self-occlusion feature of the building geometry. Considering the effects of simulation time and simulation accuracy, a value of $1 \mathrm{~m}$ was selected as the final grid size of the case study. Therefore, the intensity of radiation is computed for all surfaces of the study area with the L3 model. The solar radiation rate is computed per square meter $\left(\mathrm{kwh} / \mathrm{m}^{2}\right)$.

For the hourly cumulative value of solar radiation, Fig. 9 shows the differences between the measured values and simulated values.

As can be seen from this Figure 9, the simulated and measured values of the four different periods showed numerical differences, but are roughly the same. For example, at 12 o 'clock on the summer solstice, the accumulated value of solar radiation measured on that day was $3.488 \mathrm{kWh} / \mathrm{m}^{2}$, while the simulated value of Ladybug at the same time was $3.223 \mathrm{kWh} / \mathrm{m}^{2}$. The simulated and measured values tend to be approximately the same over time during the day.

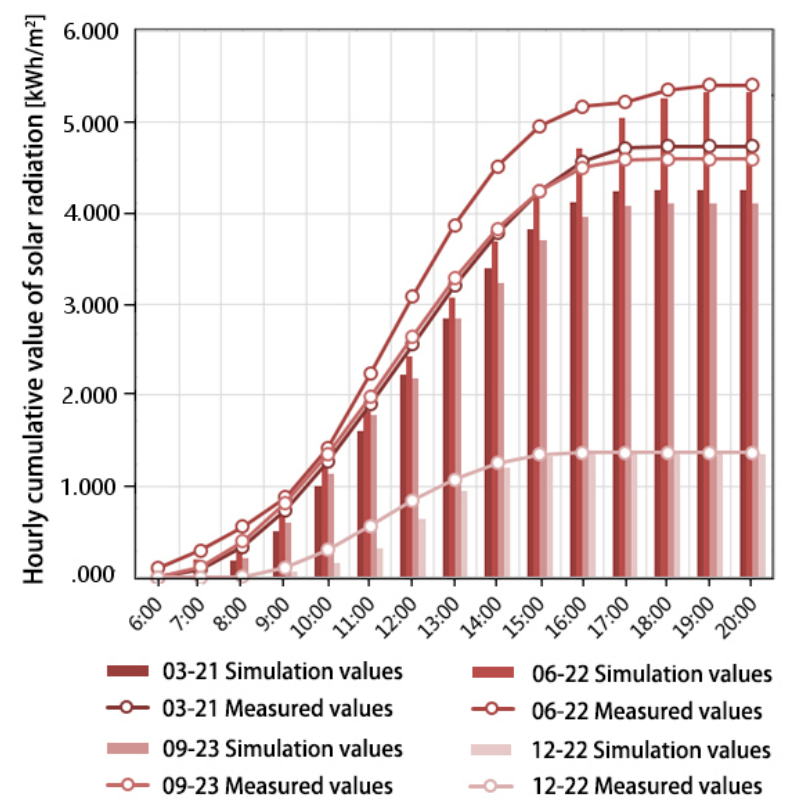

Figure 9: Hourly cumulative value of solar radiation.

The simulated and measured values were screened and extracted into 60 groups. The measured values and the corresponding simulated values were fitted to the linear regression analysis, as shown in Fig.10. The results show that the simulated values and the measured values have a high degree of fit, the Pearson correlation coefficient is $99.6 \%$, and the coefficient of determination $\mathrm{R}^{2}$ is $99.1 \%$, which is significant at the 0.01 level. The experimental results verify that the previous proposed urban context modeling and simulation processes based on UAV photogrammetry can accurately predict solar energy potential.

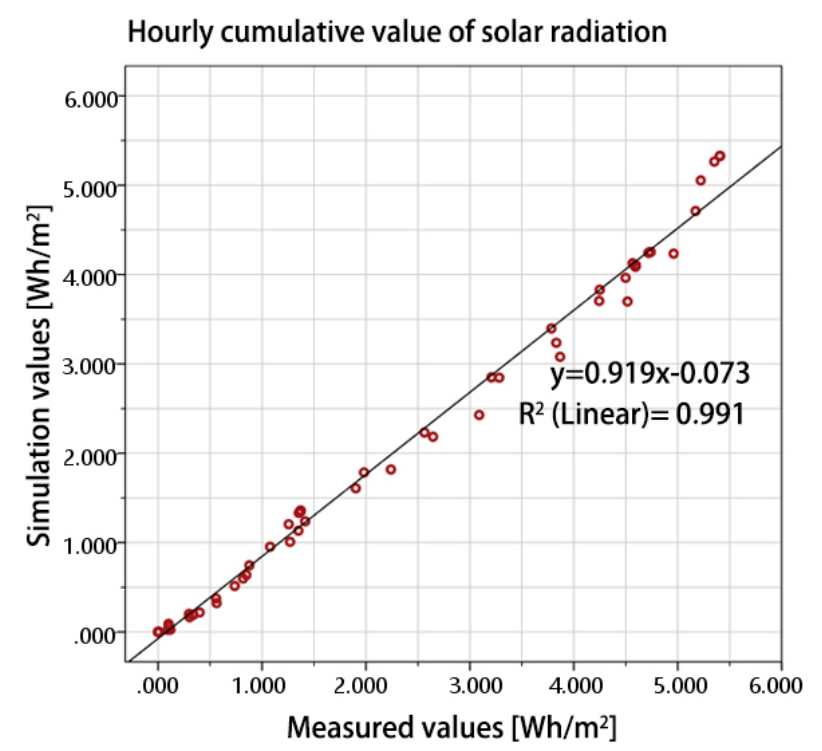

Figure 10: Linear regression plot of simulated and measured values.

\section{The effect of urban context on solar potential}

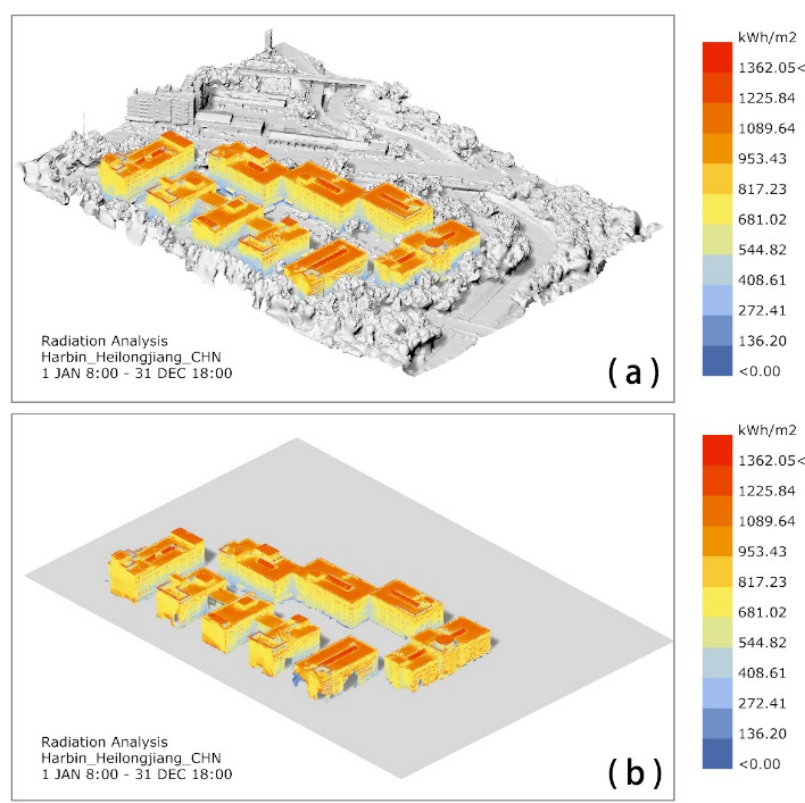

Figure 11: Comparison of annual solar radiation with or without urban context.

To assess the effect of the urban context on the solar potential of the buildings of the study area, a comparison of annual solar radiation with or without urban context was conducted. The results were shown in Figure 11. It 
can be seen from the Figure 11 that the surrounding environment has a significant impact on the solar radiation of the building, mainly on the facade. The shadow of adjacent buildings, vegetation and urban facilities seriously affect the solar irradiance acquired.

Table 7: Difference of monthly solar radiation with or without context.

\begin{tabular}{|c|c|c|c|c|}
\hline Month & $\begin{array}{c}\text { Without } \\
\text { context }\end{array}$ & $\begin{array}{c}\text { With } \\
\text { context }\end{array}$ & $\begin{array}{c}\text { Difference } \\
\text { value }\end{array}$ & $\begin{array}{c}\text { Influen } \\
\text { ce }\end{array}$ \\
\hline Jan & 23.09 & 20.83 & 2.26 & $10.8 \%$ \\
\hline Feb & 28.70 & 26.77 & 1.93 & $7.2 \%$ \\
\hline Mar & 48.78 & 46.74 & 2.04 & $4.4 \%$ \\
\hline Apr & 50.72 & 49.94 & 0.78 & $1.6 \%$ \\
\hline May & 55.56 & 55.34 & 0.22 & $0.4 \%$ \\
\hline Jun & 52.91 & 52.44 & 0.47 & $0.9 \%$ \\
\hline Jul & 50.89 & 50.59 & 0.3 & $0.6 \%$ \\
\hline Aug & 51.74 & 51.44 & 0.3 & $0.6 \%$ \\
\hline Sep & 45.63 & 44.37 & 1.26 & $2.8 \%$ \\
\hline Oct & 36.09 & 33.88 & 2.21 & $6.5 \%$ \\
\hline Nov & 23.59 & 21.32 & 2.27 & $10.6 \%$ \\
\hline Dec & 20.73 & 18.46 & 2.27 & $12.3 \%$ \\
\hline Annual & 516.28 & 445.87 & 16.31 & $15.7 \%$ \\
\hline
\end{tabular}

In addition, differences between with and without urban context were performed for each month to quantify the impact as shown in Table 7, one can conclude that the surrounding context, however relevant it may be, has always impact on the solar irradiation of surfaces, the magnitude of which depending on the season.
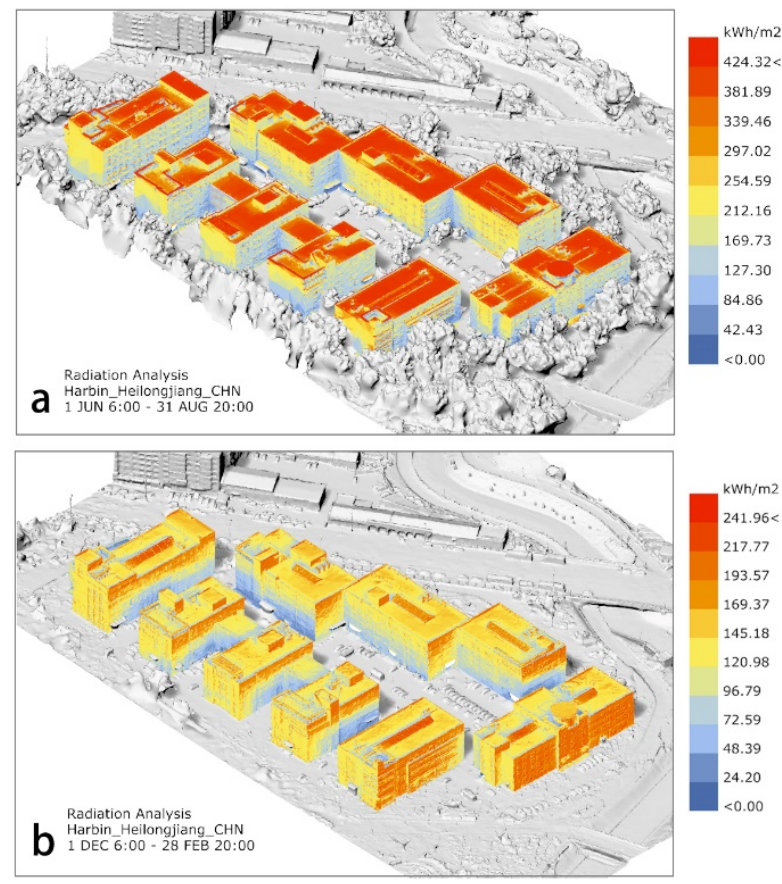

Figure 12: Comparison of seasonal solar radiation where trees shed their leaves. (a) summer. (b) winter

To evaluate the impact of seasonal changes in vegetation on solar irradiance of buildings, the paper compared the seasonal solar radiation in summer and winter. Fig. 12 showed that the simulation objects with vegetation have a remarkable effect on the solar irradiation of facades in the summer but a little effect in the winter due to the fallen leaves in this period. But the effect was limited to cold areas where trees shed their leave such as this study area.

For areas where the vegetation is evergreen, Figure 13 (a) and (b) show the results of the solar potential evaluation. Since the average height of buildings in this research area is similar, the roof is not obviously shaded by shadows, but the facade is heavily shaded by surrounding buildings and trees. Especially in winter, the energy obtained from the facade is obviously different due to the low angle of the sun. It can be seen that: in winter, the shade of trees and buildings will significantly reduce the available solar energy; in summer, the sun is at a high Angle, so the shadows are shorter and the weakening is not obvious.

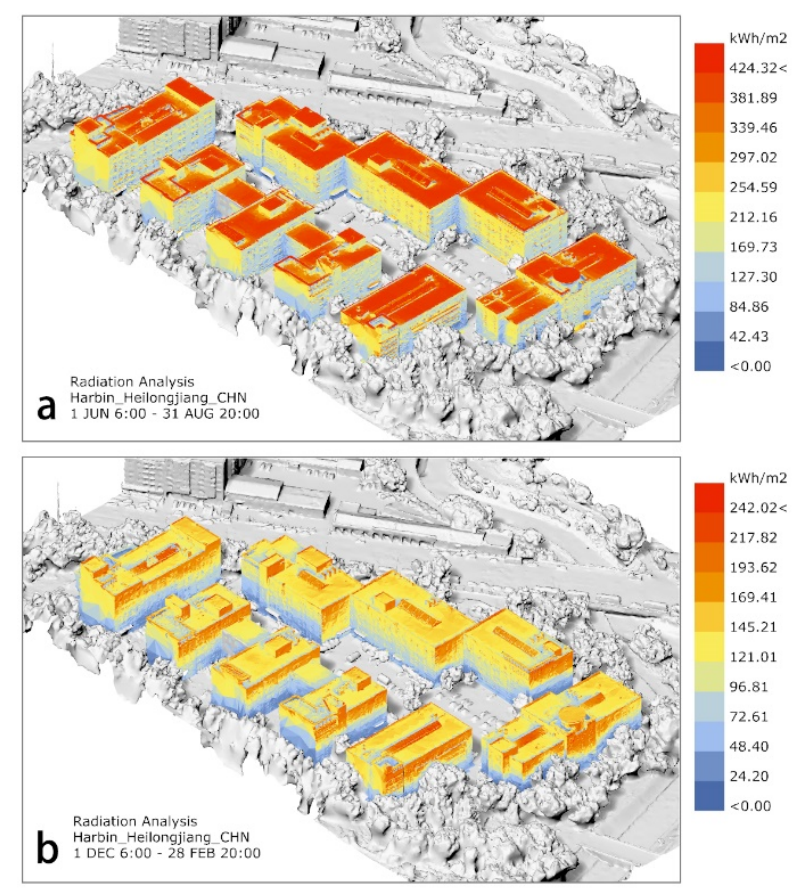

Figure 13: Comparison of seasonal solar radiation where the vegetation is evergreen. (a) summer. (b) winter

\section{Conclusion}

The impact of the urban context on the incident solar radiation on building surfaces was assessed by coupling a urban context modeling approach using UAV photogrammetry. Concerning the results, it can be concluded that the solar potential results were shown to be highly affected by the built environment. Comparing the simulation results with and without urban context (relief and surrounding buildings) an average difference in the order of $15.7 \%$ was found. In this paper four representative days (spring and autumn equinox, winter and summer solstices) were used for the solar potential evaluation, for the design of active solar energy systems and assessment of their contribution to help satisfy building energy demands, more extended time periods should be considered. Overall, the visualized annual solar radiation can be used for guided installing different types of solar collectors, making it easy to select the location that is most likely to get the maximum amount, while discovering other locations that also have solar potential but are not visually predictable. 
The method presented in this paper can be applied to solar radiation evaluation, and the results can be used in energy saving to raise awareness of the use of renewable energy. In addition, the proposed method can be easily extended to solar potential assessments of different building types by images acquired from different environments.

\section{Acknowledgement}

The authors would like to acknowledge that this paper was financially supported by the National Natural Science Foundation of China (Grant No. 51708149), and the China Postdoctoral Science Foundation (Grant No. 2017M621276). Project funded by Heilongjiang Postdoctoral Science Foundation (Grant No. LBHZ17076) and the Fundamental Research Funds for the Central Universities (Grant No. HIT.NSRIF.201838).

\section{References}

Kannan, N. , \& Vakeesan, D. . (2016). Solar energy for future world: - a review. Renewable and Sustainable Energy Reviews, 62, 1092-1105.

Freitas, S., Catita, C. , Redweik, P. , \& Brito, M. C. . (2015). Modelling solar potential in the urban environment: state-of-the-art review. Renewable and Sustainable Energy Reviews, 41, 915-931.

Romero Rodríguez, Laura, Duminil, E. , Sánchez Ramos, José, \& Eicker, U. . (2017). Assessment of the photovoltaic potential at urban level based on $3 \mathrm{~d}$ city models: a case study and new methodological approach. Solar Energy, 146(Complete), 264-275.

Carneiro, C. , Morello, E., Ratti, C. , \& Golay, F. . (2009). Solar radiation over the urban texture: lidar data and image processing techniques for environmental analysis at city scale. Forest Ecology \& Management, 189(8), 842-850.
Redweik, P. , Catita, C. , \& Brito, M. . (2013). Solar energy potential on roofs and facades in an urban landscape. Solar Energy, 97(Complete), 332-341.

Zhang, X. , Lv, Y. , Tian, J. , \& Pan, Y. . (2015). An integrative approach for solar energy potential estimation through $3 \mathrm{~d}$ modeling of buildings and trees. Canadian Journal of Remote Sensing, 41(2), 126-134.

Machete, R., Falcão, A. P., Gomes, M. G., \& Rodrigues, A. M. (2018). The use of 3D GIS to analyse the influence of urban context on buildings' solar energy potential. Energy and Buildings, 177, 290-302.

Ruzgienè, B., Berteška, T., Gečyte, S., Jakubauskienė, E., \& Aksamitauskas, V. Č. (2015). The surface modelling based on UAV Photogrammetry and qualitative estimation. Measurement, 73, 619-627.

Zhang, W., Zhang, Y., Li, Z., Zheng, Z., Zhang, R., \& Chen, J. (2017). A rapid evaluation method of existing building applied photovoltaic (BAPV) potential. Energy and Buildings, 135, 39-49.

Yongjie Pan. (2020, January). Research on building environment information modeling technology driven by UAV image data and its application. Master Thesis. Harbin Institute of Technology. Harbin.

Szabó, S., Enyedi, P., Horváth, M., Kovács, Z., Burai, P., Csoknyai, T., \& Szabó, G. (2016). Automated registration of potential locations for solar energy production with Light Detection And Ranging (LiDAR) and small format photogrammetry. Journal of Cleaner Production, 112, 3820-3829

Robinson, D., \& Stone, A. (2004, September). Irradiation modelling made simple: the cumulative sky approach and its applications. In PLEA Conference (pp. 19-22). 